\title{
Implication of anterior septal malalignment in isolated ventricular septal defect
}

\author{
Mei-Hwan Wu, Jou-Kou Wang, Chung-I Chang, Ing-Sh Chiu, Hung-Chi Lue
}

Department of Surgery, National Taiwan University, Taipei, Taiwan, Republic of China $\mathrm{M}-\mathrm{H}$ Wu

J-K Wang

C-I Chang

I-S Chiu

H-C Lue

Correspondence to: Dr M-H Wu, Department of Pediatrics, National Taiwan University Hospital, No 7 Chung-Shen South Road, Taipei, Taiwan 100 Republic of China.

Accepted for publication 19 January 1995
Objective-The aim was to define the long term prognosis of isolated ventricular septal defect (VSD) with anteriorly malaligned outlet septum.

Design-Cohort study.

Setting-University hospital, tertiary medical care centre.

Patients-Between July 1986 and June 1993, 63 patients were studied with an isolated VSD and anteriorly malaligned outlet septum (59 perimembranous; 4 muscular outlet).

Main outcome measures-The diagnosis of septal malalignment, aneurysmal transformation, right ventricular obstruction, subaortic ridge, and aortic valve prolapse was based on echocardiographic criteria, then confirmed by angiography in 33 patients and by surgery in 28. An actuarial curve for each event was obtained by Kaplan-Meier non-parametric analysis and the significance was examined by log-rank test.

Results-Aneurysmal transformation decreased the size of the VSD in $52 \%$ of the patients, but was also associated with the appearance of subaortic ridge ( $p<$ 0.05). Progressive obstruction in the right ventricle was observed in $51 \%$, more often in those without aneurysmal transformation $(p<0.05)$. Aortic valve prolapse was quite common whether or not aneurysmal transformation occurred (33\% and $23 \%$, respectively). This was attributed to the location of the VSD and the anterior malalignment of the outlet septum. Surgery was performed in 28 patients at a median age of 50 months because of significant left to right shunt $(n=5)$, or the development of obstruction in right ventricle $(n=9)$, aortic valve prolapse $(n=3)$, or combinations $(n=$ 11). The presence of subaortic ridge per se was not considered to be a surgical indication.

Conclusions-Anteriorly malaligned VSDs have variable presentation. Careful echocardiographic evaluation is needed to identify various combinations of progressive right ventricular obstruction, aneurysmal transformation, subaortic ridge, or aortic valve prolapse. In extreme cases a patient may have a pathology complex comprising right ventricular outflow obstruction, subaortic ridge, aortic valve prolapse, and anteriorly malaligned VSD.
(Br Heart f 1995;74:180-185)

Keywords: ventricular septal defect; anterior septal malalignment; prognosis

Ventricular septal defect (VSD) with anterior malalignment of the outlet septum towards the right ventricular side is usually seen in patients with the tetralogy of Fallot. ${ }^{12}$ It can also be associated with a wide right ventricular outflow tract, and cause a large left to right shunt with early pulmonary arterial hypertension. ${ }^{3}$ The term "Eisenmenger type ventricular septal defect" has been used to describe such a circumstance. However, it has recently been noted that the presence of anterior septal malalignment in patients with VSDs predisposes to the development of a subaortic ridge, aortic valve prolapse, and progressive obstruction in the right ventricle (double chambered right ventricle). ${ }^{4-6}$ The surgical pathology of these patients-which may include adhered tricuspid valve tissue on the septal defect, hypertrophic muscle in the right ventricle, a subaortic ridge, and aortic valve prolapseclearly distinguishes them from that seen in Fallot's tetralogy. ${ }^{48}$ However, previous reports on such association have been limited. It is important to define the progression of these possible complications more precisely in a cohort of patients. Therefore we conducted a longitudinal study to define the long term prognosis for patients who had initially presented with only an isolated VSD with anteriorly malaligned outlet septum.

\section{Methods}

STUDY POPULATION

From July 1986 to June 1993, 1119 patients with isolated VSD were identified from our paediatric echocardiographic laboratory. Anterior malalignment of the outlet septum towards the right ventricular side had been documented in 63 patients ( 41 boys and 22 girls). Patients with Fallot's tetralogy, or who eventually showed Fallot's tetralogy, were excluded from the study. Tetralogy of Fallot was defined in those with associated infundibular hypoplasia and obstruction, mainly at the distal ostium of the right ventricular infundibulum, though the obstruction in a double chambered right ventricle was at the proximal ostium of the infundibulum, and was usually caused by excessive or high take off moderator bands, or a combination of both. The presence of pulmonary valvular 
A

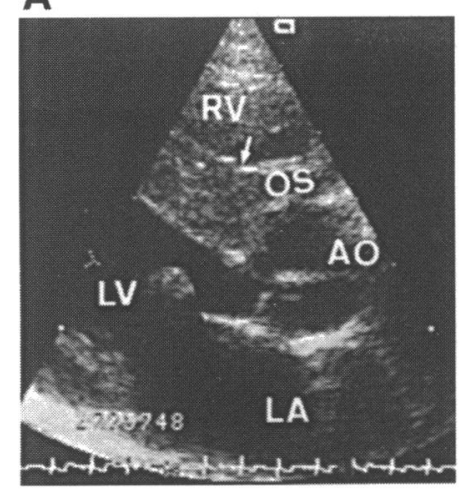

D

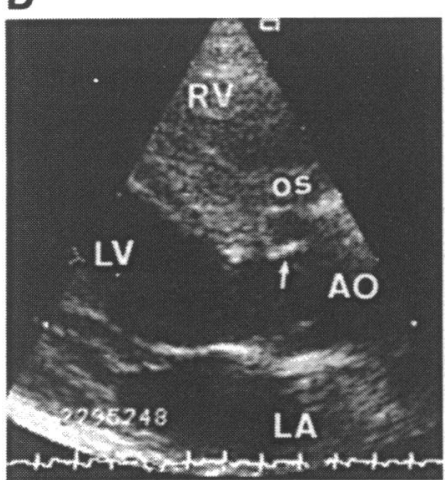

B

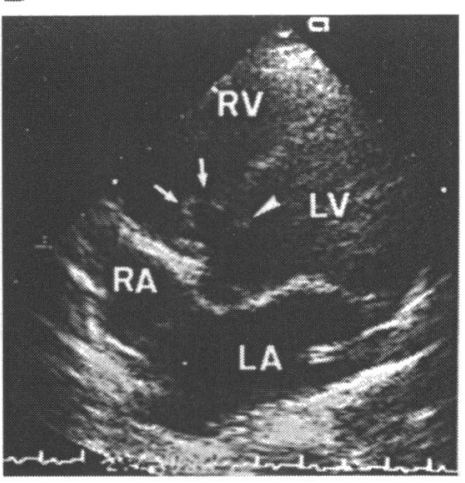

E

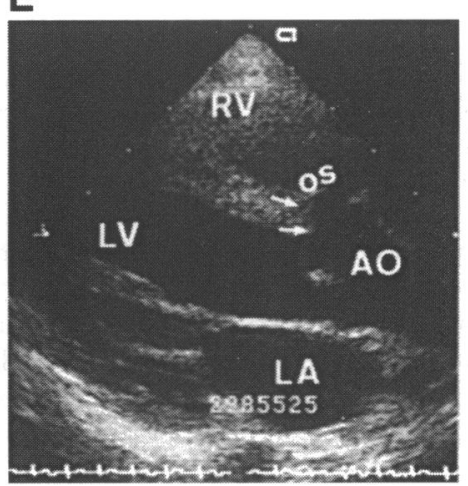

C

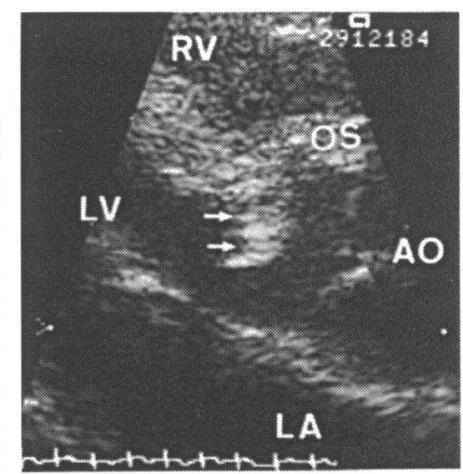

$\mathbf{F}$

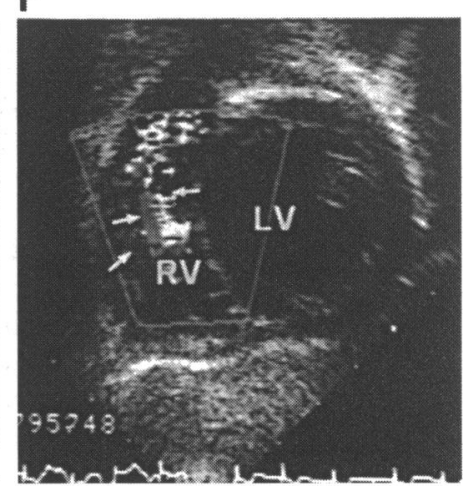

Figure 1 Echocardiographic criteria. (A) Anterior septal malalignment of the outlet septum (OS; arrow) is seen in parasternal long axis view. (B) Aneurysmal transformation over the ventricular septal defect (VSD) was derived from tricuspid valve or the adjacent tissues which formed a sac-like structure over the defect (arrow), apical five chamber view. (C) A subaortic ridge (arrow) is seen in the parasternal long axis view; a subaortic ridge can also be seen in (B) (arrowhead). (D) Right coronary cusp of the aortic valve herniated through the VSD (arrow) which was partly attributed to the anteriorly malaligned outlet septum. (E) During diastole, deformed aortic cusp is still evident (arrow). (F) Narrow right ventricular outflow tract caused by anomalous muscle (arrow) with systolic turbulence is seen at the subcostal short axis view. $A O=$ aorta; $L A=$ left atrium; $L V=$ left ventricle; $O S=$ outlet septum; $R A=$ right atrium; $R V=$ right ventricle.

stenosis or peripheral pulmonary arterial stenosis also suggested the diagnosis of Fallot's tetralogy.

Echocardiographic studies were performed with an Acuson $128 \mathrm{XP}$ module (from June 1991 to June 1993) or an Aloka 880 module (from Jan 1986 to May 1991) with colour, pulsed, and continuous wave Doppler capacities. The studies were recorded on videotape and were independently reviewed by at least two of the authors. Cardiac pathology was confirmed by cardiac catheterisation (in 33 patients) and surgery (in 28 patients).

\section{DEFINITION AND DIAGNOSTIC CRITERIA}

Localisation of the VSD was made according to previous reports. ${ }^{910}$ The VSD was morphologically characterised as perimembranous, muscular, or subarterial. Anterior malalignment of the outlet septum was diagnosed from the echocardiographic findings of anterior deviation of the outlet septum toward the right ventricular side on the parasternal long axis view (fig 1A). ${ }^{511}$ Care was taken not to produce a false positive picture as a result of a too cephalad position of the transducer. Aneurysmal transformation was defined as a sac-like structure over the VSD, which protruded into the right ventricle during systole and less so during diastole (fig 1B). ${ }^{4} \mathrm{~A}$ subaortic ridge indicated a protrusion from the crest of interventricular septum into the left ven- tricular outflow tract seen in the parasternal long axis or apical five chamber views, and was not necessarily associated with a pressure gradient through this ridge (fig $1 \mathrm{~B}$ and C). ${ }^{4512}$ Aortic valve prolapse was diagnosed when a deformed aortic cusp pivoted from the crest of the interventricular septum, noticeable in a parasternal long axis view (fig $1 \mathrm{D} \& \mathrm{E}$ ). ${ }^{13}{ }^{14}$ Obstruction in the right ventricle was defined as the presence of systolic turbulence through the right ventricular outflow tract caused by echodense structures protruding at right angles to the interventricular septum and right ventricular free wall (fig 1F). ${ }^{15}$ Since the estimation of right ventricular outflow obstruction gradient might be limited because of mixing with the jet of the VSD, only those catheterisation derived pressure gradients through the right ventricular outflow tract were analysed.

\section{STATISTICS}

Data are expressed as mean (SD). Actuarial event-free curves were obtained by using Kaplan-Meier analysis to calculate the expected probability of events. ${ }^{16}$ The differences between curves were evaluated by the log-rank test. ${ }^{17}$ Probability was defined as the percentage of events expected during a set period of time, given that the condition was diagnosed at a specific age. For calculation of each actuarial event-free curve, the follow up 


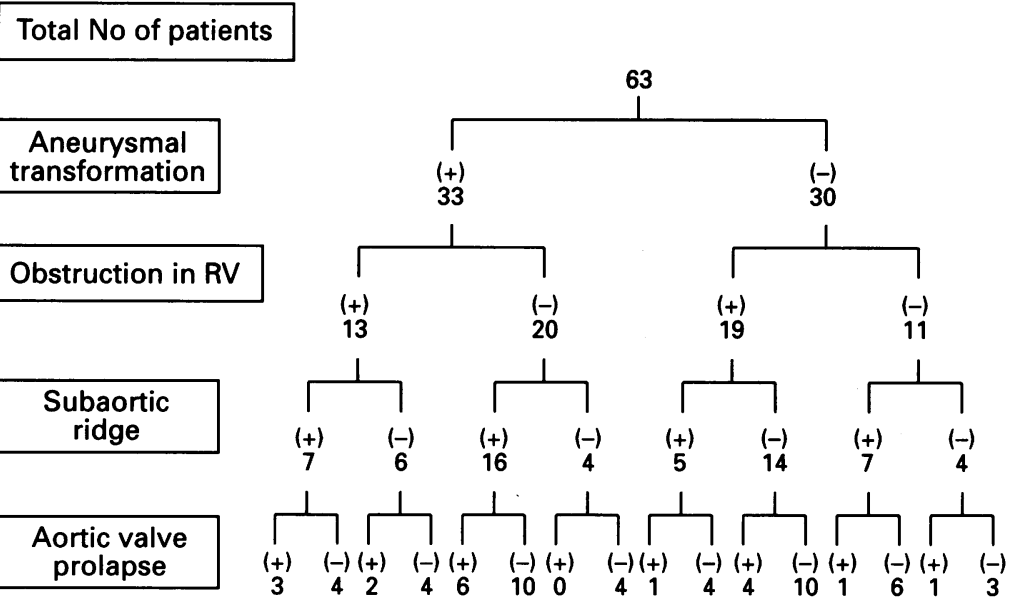

Figure 2 The frequency of the appearance of aneurysmal transformation, obstruction in right ventricle $(R V)$, subaortic ridge, and aortic valve prolapse in patients with ventricular septal defect and anteriorly malaligned outlet septum.

period of a case ended at the time the event occurred. The follow up period for those receiving surgical correction ended at the time of surgery. The association between the frequency of events was tested by Fisher's exact probability test.

\section{Results}

Median follow up period of these 63 patients was 45 months (mean 46, SD 40, months). Median age for surgery was 50 months (mean 49 , SD 41 , months).

LOCATION OF VENTRICULAR SEPTAL DEFECT The echocardiograms showed a perimembranous VSD in 59 patients and a muscular outlet VSD in the other four. These four patients all developed progressive obstruction in the right ventricle during the subsequent follow up, and two had combined aortic valve prolapse.
The aneurysmal transformation process occurred exclusively in patients with perimembranous VSD. Left ventricular angiograms confirmed the location of the VSD in 32 patients.

FREQUENCY OF LESIONS IN SUBSEQUENT FOLLOW UP

The frequency of development of aneurysmal transformation, subaortic ridge and aortic valve prolapse in the subsequent follow up is summarised in fig 2. An analysis of the association between these lesions showed that only the subaortic ridge development was closely related to the appearance of aneurysmal transformation $(P<0.01)$, and there were no significant associations between the rest of the lesions. Nonetheless progressive obstruction in the right ventricle tended to be present in those without aneurysmal transformation.

\section{DEVELOPMENT OF OBSTRUCTION IN THE}

\section{RIGHT VENTRICLE}

By actuarial analysis, event-free curves showing the proportion of patients with progressive obstruction in the right ventricle were obtained both from patients with and without aneurysmal transformation (fig 3). Patients without aneurysmal transformation are prone to have progressive obstruction in the right ventricle at subsequent follow up $(P<0.05)$. By the age of 60 months, the chance of having obstruction in the right ventricle was $46 \%$ and $64 \%$, respectively, for those with and without aneurysmal transformation. The median highest pressure gradient between the right ventricular outflow tract was $36 \mathrm{~mm} \mathrm{Hg}$ [37 (20) $\mathrm{mm} \mathrm{Hg}$. The severity of right ventricular obstruction was not related to the location of ventricular septal defect, the presence of aneurysmal transformation, or the development of subaortic ridge and aortic valve prolapse.
Figure 3 Actuarial event-free curves show the probability of having right ventricular obstruction in patients with and without aneurysmal transformation at each follow up time period. The numbers in parentheses indicate the numbers of patients still receiving follow up at that time period. The definition of follow up period is described in Methods.

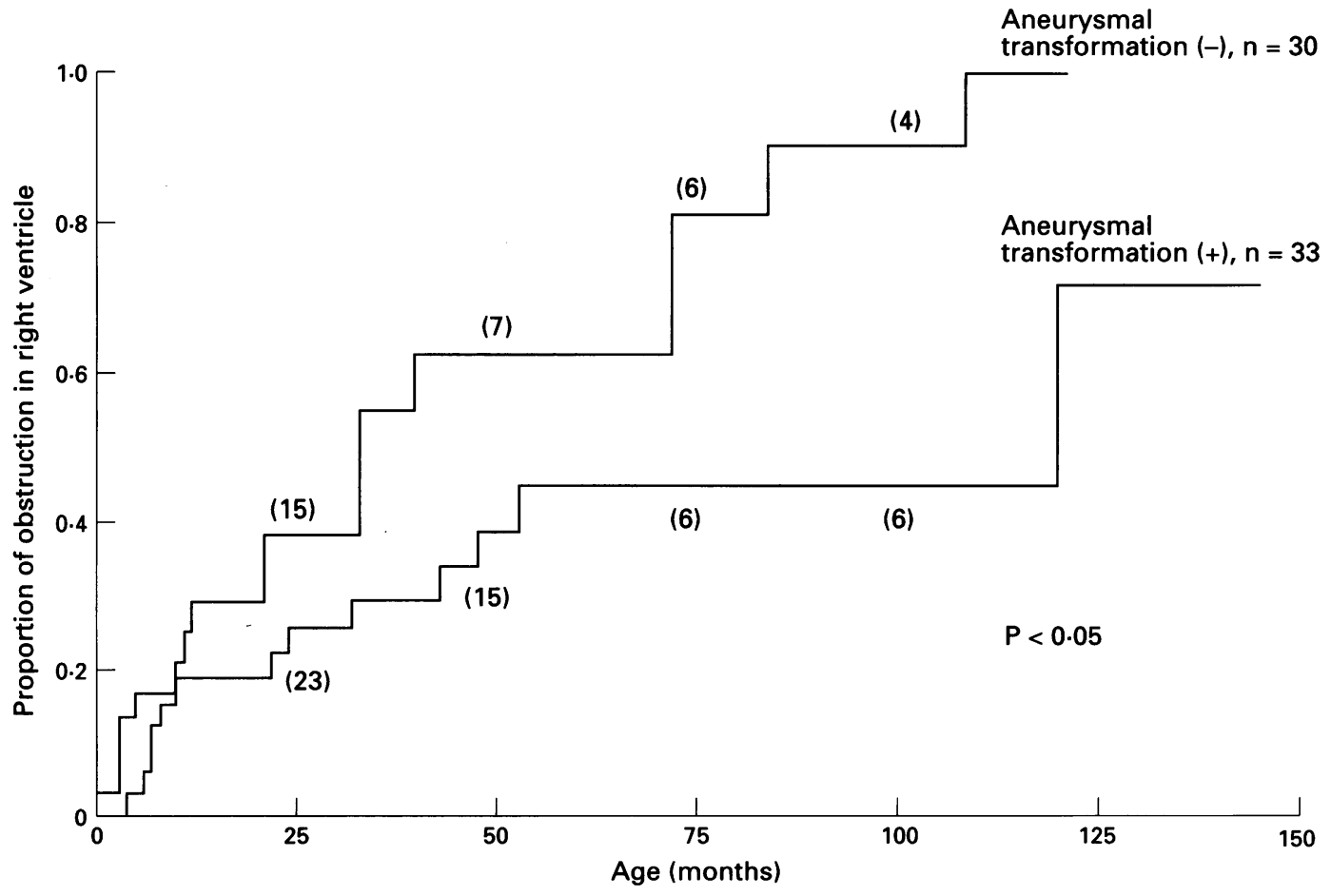


Figure 4 Actuarial eventfree curves show the proportion of patients having subaortic ridge in those with and without aneurysmal transformation at each follow up time period. Numbers in parentheses as in fig 3.

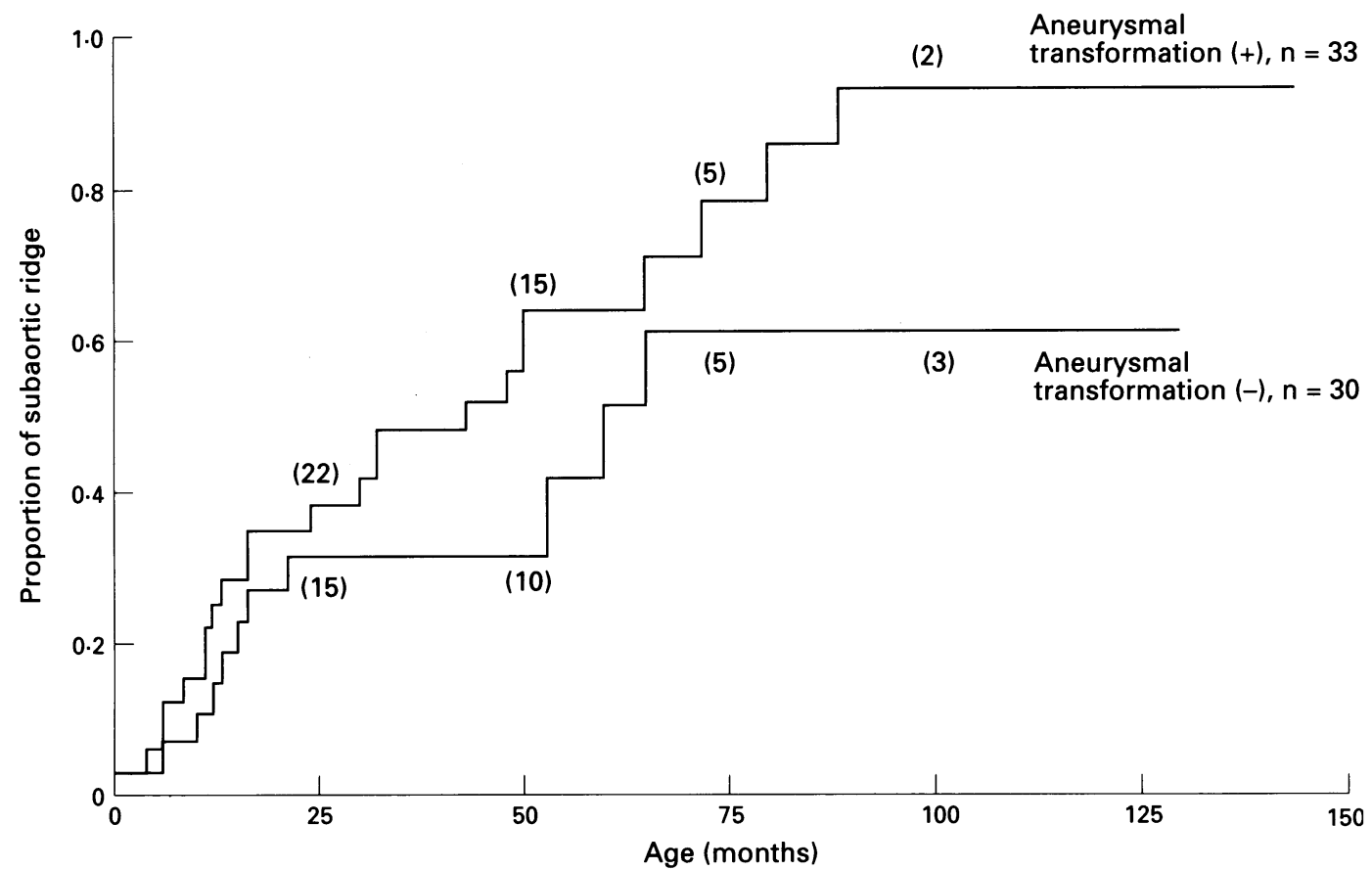

DEVELOPMENT OF SUBAORTIC RIDGE AND AORTIC VALVE PROLAPSE

By actuarial analysis, patients with aneurysmal transformation tended to have a higher chance of developing a subaortic ridge (fig 4) $(P<0.05)$. By the age of 60 months, the chance of having a subaortic ridge was $64 \%$ and $42 \%$, respectively, for patients with and without aneurysmal transformation. Doppler echocardiography showed progressively accelerated flow in the left ventricular outflow tract in 12 patients [pressure gradient $23(9) \mathrm{mm} \mathrm{Hg}$ ].

Aortic valve prolapse occurred in a substantial number of patients (fig 5). However, no significant differences were noted between those with and without aneurysmal transformation $(P=0 \cdot 10)$. Mild aortic regurgitation was found in six patients.
HAEMODYNAMIC DATA AT CATHETERISATION Cardiac catheterisation was performed in 33 patients at a median age of 45 months [50(38) months] because of the presence of right ventricular outflow tract obstruction, aortic valve prolapse, or subaortic ridge detected on echocardiography (29 cases), or significant left to right shunt suspected by the clinical picture (four cases). The median ratio of pulmonary to systemic flow was $1.5[1 \cdot 68(0 \cdot 6)]$. A significant left to right shunt (pulmonary to systemic flow ratio greater than 2) was only noted in patients without obstruction in the right ventricle or aneurysmal transformation. The median ratio of pulmonary arterial to systemic pressure was $0 \cdot 26[0 \cdot 29(0 \cdot 14)]$. Higher pulmonary arterial pressure was associated with a significant left and right shunt.
Figure 5 Actuarial event-free curves show the proportion of patients having aortic valve prolapse in those with and without aneurysmal transformation at each follow up time period. Numbers in parentheses as in fig 3.

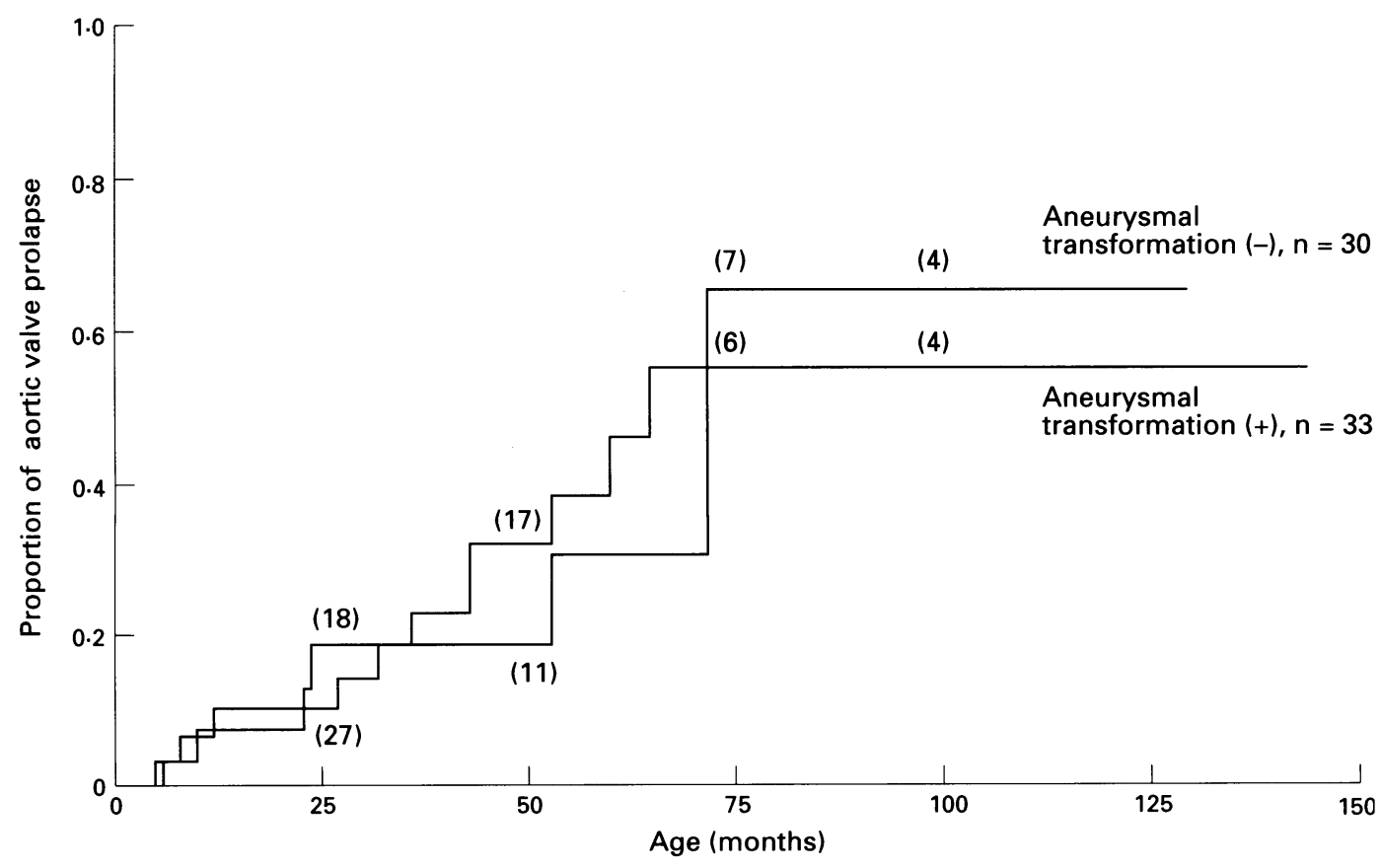


MORPHOLOGICAL DESCRIPTION DURING

\section{SURGERY}

The cardiac pathology described by echocardiography was then confirmed by surgery in 28 patients (three of them were not catheterised). Surgical indications included a large left to right shunt $[n=2$; median age 6.5 , mean $6 \cdot 5(0.7)$ months], a pulmonary to systemic flow ratio greater than 2 after 2 years of age [ $n=3$; median age 31 , mean 29(8) months], a gradient through right ventricular outflow tract greater than $30 \mathrm{~mm} \mathrm{Hg}[\mathrm{n}=9$; median age 45 , mean 56(32) months], aortic valve prolapse $[\mathrm{n}=3$; median age 10 , mean 31(26) months], a combination of aortic valve prolapse and obstruction in right ventricle [n $=6$; median age 71 , mean 74(52) months], a combination of obstruction in the right ventricle and the left ventricle or aortic regurgitation [ $\mathrm{n}=3$; median age 56 , mean $102(40)$ months], and others [ $n=2$; median age 46 , mean $46(59)$ months]. The presence of a subaortic ridge on its own was not considered to be a surgical indication. The subaortic ridge was attributed to tissue overgrowth from the crest of the interventricular septum. Fibrotic jet lesions with hypertrophic septoparietal and moderator bands in the right ventricle contributed to the progressive right ventricular obstruction. A superiorly inserted moderator band was not clearly documented in our patients. The fibrotic lesion was described as a continuation from a fibrotic complex formed by adherence of tricuspid tissue to the margin of the ventricular septal defect and the subaortic ridge in 10 cases. Prolapsing aortic valve was found herniated into the right ventricle through the septal defect and was partly aggravated by the dextroposed aorta. None of our patients had documented anomalies of the aortic valve commissure. A deformed sinus of Valsalva wall, with severe angulation towards the right ventricular outflow tract, was frequently found in patients with aortic valve prolapse.

\section{Discussion}

Infants who have congestive heart failure due to a VSD with anteriorly malaligned outlet septum are usually thought to have a variant of the tetralogy of Fallot. ${ }^{18}$ Progressive right ventricular outflow tract obstruction is expected at subsequent follow up and a diagnosis of Fallot's tetralogy will then be established. However, the progressive obstruction in the right ventricle in patients with ventricular septal defect has often been described as a double chambered right ventricle, which is characterised by muscular narrowing which partitions the ventricle into an inflow and outflow chamber and is distinct from the tetralogy of Fallot. $^{19}$ Furthermore, a close association between the development of a subaortic ridge and the presence of anterior septal malalignment has been described in patients with a VSD. ${ }^{45}$ Additionally, a malaligned VSD may also be associated with a wide right ventricular outflow tract and increased pulmonary flow, with early pul- monary arterial hypertension. ${ }^{3}$ Therefore the natural history of those patients who initially have an isolated VSD with an anteriorly malaligned outlet septum needs to be clarified. Our longitudinal study of 63 patients with isolated anteriorly malaligned VSD, excluding those with Fallot's tetralogy, confirms a wide clinical spectrum in this disease entity.

Progressive obstruction in the right ventricle occurred in about half the patients with isolated VSD and anteriorly malaligned outlet septum. Although the clinical features at the time an obstruction was evident might simulate those seen in Fallot's tetralogy, the right ventricular outflow lesion as disclosed during surgery was not caused by an antero-cephalad deviation of the outlet septum, as suggested for Fallot's tetralogy; instead it was attributed to the combination of a fibrotic band and a hypertrophic septoparietal and moderator band muscle in the right ventricle. Such an anomalous right ventricular muscle bundle has been suggested as an acquired lesion in patients with VSDs and divides the right ventricle into two chambers, the so called "double chambered right ventricle". ${ }^{819}$ In a substantial number of patients, a subaortic ridge developed in the subsequent course, especially in those in whom tricuspid tissue adhered to the defect margins. Furthermore, aortic valve prolapse was noted in about one third of the patients. These late complications could clearly further distinguish these patients from those with Fallot's tetralogy.

A close association between the presence of anterior septal malalignment and a subaortic ridge had been described by Zielinsky et al. ${ }^{5}$ In their series, apposition of tricuspid valve tissue over the margins of the VSD was observed in about two thirds of the patients. Our own data also indicate that diminution of the size of the defect by the aneurysmal transformation process may occur in patients with a VSD and an anteriorly malaligned outlet septum. However, this closing mechanism was found to be closely associated with the development of a subaortic ridge. Therefore, it is suggested that in patients with a VSD, the presence of anterior malalignment of the outlet septum predisposes to the development of a subaortic ridge, which can be further stimulated by the appearance of the aneurysmal transformation process.

Ando and Takao reported a high incidence of aortic valve prolapse in patients with ventricular septal defect and anteriorly malaligned outlet septum. ${ }^{6}$ In $64 \%$ of their patients, a deformed sinus of Valsalva wall, with severe angulation towards the right ventricular outflow tract, was found. In about one third, they found a coexisting bicuspid aortic valve. Our study echoed their results by showing a high likelihood of developing aortic valve prolapse in patients with anteriorly malaligned ventricular septal defects. However, no significant intrinsic aortic valve anomalies were identified. It was the location of the outlet septum of the VSD which predisposed to the development of aortic valve prolapse, which 
was further facilitated, in the presence of septal malalignment, by an angulation of the sinus of Valsalva.

In conclusion, we have proved the heterogeneous nature of isolated VSD with anteriorly malaligned outlet septum. Close echocardiographic evaluation is needed to delineate the wide spectrum of clinical presentation, including various combinations of progressive obstruction in the right ventricle, aneurysmal transformation, subaortic ridge, or aortic valve prolapse. In extreme cases, a patient may have a pathology complex involving right ventricular outflow obstruction, a subaortic ridge, aortic valve prolapse, and the VSD.

The authors thank Ms Su-Chin Chien for her technical assistance and Ms Chiu-Yu Chen for her preparation of the manuscript.

1 Anderson RH, Allwork SP, Ho SY, Lenox CC, Zuberbuhler JR. Surgical anatomy of tetralogy of Fallot. f Thorac Cardiovasc Surg 1981;81:887-96.

2 Van Praagh R, Van Praagh S, Nebesar KA, Muster AJ, Sinha SN, Paul MH. Tetralogy of Fallot. Underdevelopment of the pulmonary infundibulum and its development of the pulmonary infun
sequelae. Am $\mathcal{F}$ Cardiol 1970;26:25-33.

3 Oppenheimer-Dekker A, Gittenberger-de Groot AC, Bartelings MM, Wenick ACG, Moene RJ, van der Harten JJ. Abnormal architecture of the ventricles in hearts with an overriding aortic valve and a perimembranous ventricular septal defect ("Eisenmenger VSD"). Int $\ngtr$ Cardiol 1985;9:341-55.

4 Wu MH, Wu JM, Chang CI, Wang JK, Wu YN, Chien SC, et al. Implication of aneurysmal transformation in isolated perimembranous ventricular septal defect. $A m \mathcal{F}$ Cardiol 1993;72:596-601.

5 Zielinsky P, Rossi M, Haertel JC, Vitola D, Lucchese FA, Rodrigues R. Subaortic fibrous ridge and ventricular septal defect: role of septal malalignment. Circulation 1987;6:1124-29.
6 Ando M, Takao A. Pathological anatomy of ventricular septal defect associated with aortic valve prolapse and regurgitation. Heart Vessels 1986;2:117-26.

7 Weidman W, Blount S, Dushane J, Gersony W, Hayes C, Nadas A. Clinical course in ventricular septal defect. Circulation 1977(Suppl I):56-9.

8 Pongiglione G, Freedom R, Cook D, Rowe RD. Mechanism of acquired right ventricular outflow tract obstruction in patients with ventricular septal defect: an angiographic study. Am $\mathcal{F}$ Cardiol 1982;50:776-80.

9 Baker EJ, Leung MP, Anderson RH, Fischer DR, Zuberbuhler JR. The cross sectional anatomy of ventricular septal defects: a reappraisal. Br Heart $\mathcal{F} 1988$;59: ular septal

10 Heimcke $F$, de Souza A, Nanda NC, Villacosta I, Gatewood R, Colvin E, et al. Two-dimensional and
color Doppler assessment of ventricular septal defect of color Doppler assessment of ventricular septal defe

11 Snider AR, Serwer GA. Defects in cardiac septation. In: Snider AR, Serwer GA, eds. Echocardiography in pediatric heart disease. New York: Year Book Medical Publishers, 1990:149-53.

12 Cassidy SC, Van Hare GF, Silverman NH. The probability of detecting a subaortic ridge in children with ventricular septal defect or coarctation of the aorta. Am $\mathcal{F}$ Cardiol 1990;66:505-8.

13 Craig BG, Smallhorn JF, Burrows P, Trusler GA, Rowe RD. Cross-sectional echocardiography in the evaluation of aortic valve prolapse associated with
defect. Am Heart $\mathcal{f} 1986 ; 112: 800-7$.

14 Wang JK, Lue HC, Wu MH, Young ML, Chiu IS, Chang $\mathrm{CI}$, et al. Assessment of ventricular septal defect with aortic valve prolapse by means of echocardiography and angiography. Cardiol Young 1994;4:44-50.

15 Vogel M, Smallhorn JF, Freedom RM, Coles J, Williams WG, Trusler GA. An echocardiographic study of the association of ventricular septal defect and right ventricular muscle bundles with a fixed subaortic abnormality. Am $¥$ Cardiol 1988;61:857-60.

16 Kaplan EL, Meier P. Nonparametric estimation from incomplete observation. $\mathscr{f} A m$ Stat Assoc 1958;53: 457-81.

17 Peto R, Pike MC, Armitage P. Design and analysis of randomized clinical trials requiring prolonged observation of each patients. Br f Cancer 1977;35:1-39.

18 Rowe RD, Vlad P, Keith JD. Atypical tetralogy of Fallot. Noncyanotic form with increased lung vascularity: report of four cases. Circulation 1955;12:230-8.

19 Wong PC, Sanders SP, Jonas RA, Colan SD, Parness IA Geva $T$, et al. Pulmonary valve-moderator band distance and association with development of double-chambered right ventricle. Am $\mathcal{f}$ Cardiol 1991;68:1681-6. 